\title{
Military Nurses: Caring often Invisible and Unheralded
}

\section{Ernestine Hunter Cuellar}

Associate Professor, School of Nursing, University of Texas Medical Branch, USA

Every year nurses are honored nationally during one week in May, around Florence Nightingale's birthday, May 12. Memorial Day in May is also a day in which Americans honor and remembers military members who have served or perished in service to our country. The military and nursing are inextricably connected. Let us also remember military nurses when we honor others who served in military war zones, humanitarian missions, and natural disasters.

Nightingale is recognized as one of the most significant figures impacting modern nursing, along with Mary Seacole, Dorothea Dix, and Clara Barton. Little is mentioned about the connection these women had to the military. Not only did these women impact modern nursing they were significant in gaining recognition for the importance of nursing care through their facilitating the recovery of soldiers.

Employed by the British government, Nightingale went to the Crimea to provide nursing care and relief to the catastrophic number of British soldiers who were dying. She was the first superintendent of nurses recognized by the British military. The introduction of infection control was one of Nightingale's greatest contributions; infection control saved thousands of lives in the Crimea. Other Nightingale contributions to modern nursing were the inauguration of trained nurses into the care of soldiers as well as maintaining statistical data (a first small step in evidence based nursing practice).

Although Mary Seacole, a Jamaican healer, did not become part of Nightingale's contingency; Seacole, however, provided nursing care for other wounded and ill British soldiers using the profits she earned from a hotel she owned in the Crimea. Nightingale's group received heavy political and public criticism for her inclusion of Catholic and Anglican sisters. It is speculated that was one reason Nightingale did not include Seacole. The prevailing prejudice was that those religious women would go to the Crimea to save souls rather than focus on restoring health to the body. At the time little credence was given to the connection of mind, body and spirit.

The U.S. military sent a group of observers to the Crimea to gain firsthand knowledge about medical and nursing care in a war zone. Later information gleaned from the observers was used, during the American Civil War, to employ Dorothea Dix as the superintendent of hospitals modeled on Nightingale's role in the Crimea. Years later, based on her observations, Clara Barton established the American Red Cross, a group that effectively provided nurses for military service from the Spanish American War through WWII. The Catholic sisters were prominent in meeting the needs of the military in the Civil War, Confederate and Union, and later U.S. Wars.

As we recognize and remember nurses during Nurses' Week let us also honor and remember those nurses who provided nursing care to soldiers, sailors, airmen, and marines since Nightingale's excursion to the Crimea. In addition to saving lives in austere surroundings military nurses have also introduced new roles for nurses. Imagine being the first male nurse in a Nurse Corps of 3500 women! Although we frequently speak of equality of gender among nurses it is fascinating to learn that it wasn't until 1956 that male nurses were allowed to join the Army Nurse Corps. Since that time $40 \%$ of military nurses are male as opposed to the $4-6 \%$ male nurse population in the civilian sector. The US Army introduced Flight nursing and aero medical evacuation, in 1941, during World War II. Certified Registered Nurse Anesthetists (CRNA) gained popularity in the military.
These women and men volunteer to work in austere settings to provide caring to their fellow soldiers, sailors, airmen, and marines. In addition since the Civil War African American nurses also volunteered to provide military nursing care even when their services were neither wanted nor appreciated. Eleanor Roosevelt, Estelle Osborne, and Mabel Staupers, another Jamaican, labored for integration of African American nurses into the military during WWII at the same time that the Tuskegee Airmen were lobbying to fly flight and win for the US Army Air Corps.

As we place flags, flowers, and wreathes to honor our loved ones on Memorial Day let us also recall those nurses who went above and beyond the call of duty when they volunteered to serve in the Civil War, Spanish American War, WWI, WWII, Korea, Vietnam, Desert Storm, and the wars in Iraq and Afghanistan, as well as Kosovo, Somalia, humanitarian missions throughout the world, for manmade or natural disasters such as Hurricane Katrina, Haiti, and Japan. At Arlington National Cemetery visit Section 21, the Nurses' Section; look for the nurse's white cap on the Korean Wall mural. Let us not forget those Army and Navy nurses who were interned by the Japanese (medical/ nursing personnel are not called POW). Finally, we should remember those who died in service to the country, Dolly Vinsant, a flight nurse in WWII and others at Anzio, Sharon Lane and at least 8-10 others in Vietnam (their names are on the Vietnam Wall), and Maria Ortiz in Iraq (first U.S. nurse killed in a war zone since Vietnam).

\section{The Wound Dresser}

Walt Whitman (served as nurse during Civil War)

...bearing the bandages, water, and sponge

Straight and swift to the wounded I go

Where they lie on the ground after the battle brought in, hospital

...or to the long rows of the hospital tent, or under the roofed (sic)

...I onward go, I stop with hinged knees and steady hand to dress wounds

...I am faithful, I do not give out, the fractured (sic) thigh, the knee, the wound in the abdomen, these and more I dress with impassive hand (yet deep in my breast a fire, a burning flame)... returning, resuming, I thread my way through the hospitals,

The hurt and wounded I pacify with soothing hand,

I sit by the restless all the dark night, some are so young,

Some suffer so much; I recall the experience sweet and sad...

Corresponding author: Ernestine Hunter Cuellar, Associate Professor, Schoo of Nursing, University of Texas Medical Branch, USA, E-mail: ehcuella@utmb.edu

Received May 23, 2012; Accepted May 25, 2012; Published May 28, 2012

Citation: Cuellar EH (2012) Military Nurses: Caring often Invisible and Unheralded. J Nurs Care 1:e110. doi:10.4172/2167-1168.1000e110

Copyright: ( 2012 Cuellar $\mathrm{EH}$. This is an open-access article distributed under the terms of the Creative Commons Attribution License, which permits unrestricted use, distribution, and reproduction in any medium, provided the original author and source are credited. 